\title{
Study of Mental Activity and Regular Training (SMART) in at risk individuals: A randomised double blind, sham controlled, longitudinal trial
}

\author{
Nicola J Gates ${ }^{1 *}$, Michael Valenzuela ${ }^{1,2,3}$, Perminder S Sachdev ${ }^{1,2,4}$, Nalin A Singh ${ }^{5,6}$, Bernhard T Baune ${ }^{7}$, \\ Henry Brodaty ${ }^{1,2,8}$, Chao Suo ${ }^{1}$, Nidhi Jain ${ }^{9}$, Guy C Wilson ${ }^{9}$, Yi Wang ${ }^{9}$, Michael K Baker ${ }^{9}$, Dominique Williamson ${ }^{9}$, \\ Nasim Foroughi ${ }^{9}$ and Maria A Fiatarone Singh ${ }^{9,10}$
}

\begin{abstract}
Background: The extent to which mental and physical exercise may slow cognitive decline in adults with early signs of cognitive impairment is unknown. This article provides the rationale and methodology of the first trial to investigate the isolated and combined effects of cognitive training $(C T)$ and progressive resistance training (PRT) on general cognitive function and functional independence in older adults with early cognitive impairment: Study of Mental and Regular Training (SMART). Our secondary aim is to quantify the differential adaptations to these interventions in terms of brain morphology and function, cardiovascular and metabolic function, exercise capacity, psychological state and body composition, to identify the potential mechanisms of benefit and broader health status effects.

Methods: SMART is a double-blind randomized, double sham-controlled trial. One hundred and thirty-two communitydwelling volunteers will be recruited. Primary inclusion criteria are: at risk for cognitive decline as defined by neuropsychology assessment, low physical activity levels, stable disease, and age over 55 years. The two active interventions are computerized CT and whole body, high intensity PRT. The two sham interventions are educational videos and seated calisthenics. Participants are randomized into 1 of 4 supervised training groups $(2 \mathrm{~d} / \mathrm{wk} \times 6 \mathrm{mo})$ in a fully factorial design. Primary outcomes measured at baseline, 6, and 18 months are the Alzheimer's Disease Assessment Scale (ADAS-Cog), neuropsychological test scores, and Bayer Informant Instrumental Activities of Daily Living (B-IADLs). Secondary outcomes are psychological well-being, quality of life, cardiovascular and musculoskeletal function, body composition, insulin resistance, systemic inflammation and anabolic/neurotrophic hormones, and brain morphology and function via Magnetic Resonance Imaging (MRI) and Spectroscopy (fMRS).
\end{abstract}

Discussion: SMART will provide a novel evaluation of the immediate and long term benefits of CT, PRT, and combined CT and PRT on global cognitive function and brain morphology, as well as potential underlying mechanisms of adaptation in older adults at risk of further cognitive decline.

Trial Registration: Australia and New Zealand Clinical Trials Register (ANZCTR): ANZCTRN12608000489392

\section{Background}

With a forecast 100 million persons with dementia by 2050, this disorder presents a major challenge to sufferers, their caregivers, and the health care system, and delay of disease onset and progression is amongst the most pressing challenges for medical research [1]. A

\footnotetext{
* Correspondence: nicola.gates@student.unsw.edu.au

'School of Psychiatry, University of New South Wales, Randwick NSW 2031, Australia

Full list of author information is available at the end of the article
}

five-year delay in dementia onset and progression could halve disease prevalence [2] and would have a significant impact on disease burden. The efficacy of pharmacological treatments to date have been limited to symptom control [3] and have not been effective in reducing disease onset, and so non-pharmacological preventative interventions are of great interest.

There is strong evidence from cross-sectional and prospective cohort studies that participation in mentally

\section{() Biomed Central}

(c) 2011 Gates et al; licensee BioMed Central Ltd. This is an Open Access article distributed under the terms of the Creative Commons Attribution License (http://creativecommons.org/licenses/by/2.0), which permits unrestricted use, distribution, and reproduction in any medium, provided the original work is properly cited. 
and physically stimulating activities is associated with decreased dementia prevalence and/or incidence [4-9].

Experimental trials indicate that cognitive training can significantly improve performance in healthy adults on a range of cognitive tasks, with an average moderate effect size (ES) of 0.6 [10-13]; and that exercise interventions of as little as one week of aerobic exercise can result in improved memory, attention, and reaction time [14]. Sustained improvements, particularly in executive function, have been shown after aerobic training $(\mathrm{ES}=0.41)$, combined aerobic and resistance training ( $E S=0.59)$, and resistance training alone $(E S=0.53)$, even after exercise was withdrawn in some cases [15].

Two studies to directly compare single and combined physical and mental exercise found effect sizes across a range of cognitive outcomes to be much larger in the combined condition $[12,16]$. Both of these studies had design flaws, including very small sample sizes [16] and high dropout rates [12], limiting conclusions. Therefore, a robustly designed trial is required to investigate the comparative benefits of isolated and combined physical and mental training.

The mechanisms of benefit from physical and mental interventions are not clear, it has been postulated that physical and mental activity may therefore have potential to stimulate plasticity of the brain and possibly reduce dementia onset. Animal studies have demonstrated a range of positive neurobiological outcomes, including decreased inflammatory cytokines, decreased cortisol response to stressors, increased insulin-like growth factor-1 (IGF-1) into the brain, increased cerebral blood flow and angiogenesis, and increased hippocampal volume, brain derived neurotrophic factor (BDNF), neurogenesis, and synaptic density after memory-enhancing cognitive and exercise training $[7,17]$. Human data are more limited, but observations of responses to training have included increased blood flow, aerobic capacity, and region brain volume after behavioural and aerobic training $[18,19]$ and improved brain chemistry using magnetic resonance spectrometry (MRS) in our pilot work with cognitive training [20]. There are fewer human data available on the possible cognitive-enhancing mechanisms of resistance training, with findings of no changes in BDNF [21], and increases in IGF-1 [22]. Animal and human exercise trials indicate that exercise may improve brain function via two pathways; directly through the induction and regulation of growth factors (e.g., BDNF, IGF-1), and/or indirectly via the modulation of systemic inflammation [7]. However, rigorous clinical trials investigating the central and peripheral synergistic benefits of exercise for improved brain function are lacking [7]. Consequently the Study of Mental Activity and Regime Training trial (SMART) was designed and implemented to examine the isolated and combined benefits of cognitive training and resistance training, and to provide novel, comprehensive data on possible proposed links between cognitive improvement and brain and whole-body-adaptation to resistance and cognitive training.

Most cognitive and exercise training trials have targeted healthy, cognitively intact adults. The most vulnerable individuals at highest risk for cognitive decline, however, are those with early cognitive impairment and co-morbid diseases such as cardiovascular disease, type 2 diabetes, obesity, and hypertension (i.e. metabolic syndrome). We are therefore deliberately excluding high functioning volunteers and targeting a highly clinically relevant population, with evidence of early cognitive impairment and various cardiovascular risk factors. These individuals may not be capable of the moderate or high intensity aerobic training that has been shown to be effective in animal and human trials. Resistance training, which has a larger effect size in the literature (0.53) than isolated aerobic training (0.41), and comparable to combined aerobic/resistance training (0.59), may be a more realistic exercise option in this cohort, as it is more feasible in elders with frailty and mobility impairment, thus having the potential for long-term adherence. We [23] and others have shown that resistance training results in many beneficial adaptations in older adults that may be relevant to the mechanisms underlying its putative cognitive benefits. These adaptations (see Figure 1), many of which will be studied in this proposal (particularly changes in fitness, inflammation, and body composition) would not be anticipated after exposure to cognitive training alone, consequently the SMART trial will enable investigation of the efficacy of combining these two distinctly different training paradigms.

The SMART trial is a long term study that will measure evidence of both immediate and sustained benefits of training, one year after withdrawal of active treatment. In addition to the selection of general cognitive, functional, physical, mood symptoms and quality of life outcome measures will also be assessed to identify the extent of transfer of benefits of our interventions.

\section{Objectives and Hypothesis}

The primary objective of the SMART trial is to determine whether cognitive, physical or combined cognitive and physical training can prevent or slow cognitive and functional decline in vulnerable older adults at high risk of dementia. Our secondary aim is to explore adaptation to these two interventions in the brain, as well as identify potential mechanisms of benefit, in particular modulation of cardiovascular risk profile, systemic inflammatory cytokines, growth factors, fitness levels, and body composition. 


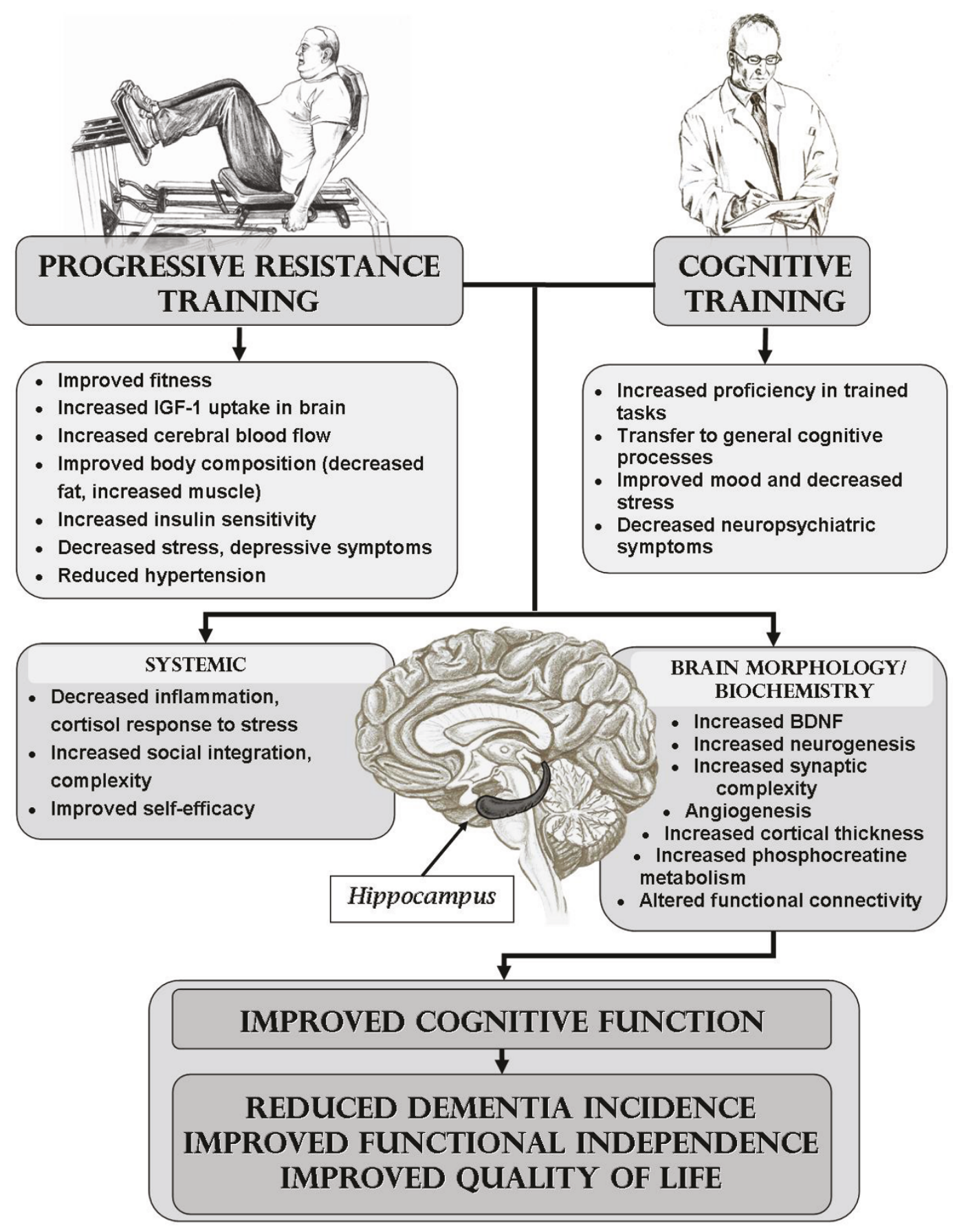

Figure 1 Theoretical model of mechanisms linkage between progressive resistance training, cognitive training, and cognitive and functional outcomes. BDNF = brain-derived neural growth factor IGF-1 = insulin-like growth factor-1.

\section{Primary Hypotheses}

1. Six months of supervised cognitive training (CT) will significantly improve cognitive function, as assessed by the Alzheimer's Disease Assessment Scale Cognitive subscale (ADAS-Cog) [24,25], and independence of function as assessed by the Bayer Informant -Activities of Daily Living (BIADL) [26] at both 6- and 18- month follow-up, relative to a sham training control condition.

2. Six months of supervised high intensity progressive resistance training (PRT) will significantly improve cognitive function, as assessed by the ADAS-Cog, and independence of function as assessed by the Bayer 
Informant -Activities of Daily Living (BIADL), at both 6and 18-month follow-up, relative to a sham training control condition.

3. The combination of CT and PRT will be significantly superior to either intervention in isolation for cognitive and functional benefits.

\section{Secondary Hypotheses}

1. All active training interventions will improve brain morphology and biochemistry compared to the sham control condition, as defined by: increased hippocampal volume $\left(\mathrm{mm}^{3}\right)$ by MRI scanning; positive localised Voxel-Based Morphometry (VBM) brain changes (zscore relative change); decreased whole brain volume of White Matter Hyper-intensities (WMHs) $\left(\mathrm{mm}^{3}\right)$; and lead to beneficial hippocampal and posterior cingulate MRS metabolite changes (\% increase in $\mathrm{N}$-acetylaspartate, and increase in phosphocreatine metabolites).

2. All active training interventions will improve secondary cognitive outcomes, in the domains of attention, memory, fluency, and executive function, relative to the sham control condition, and combined training will be superior to either single intervention.

3. All active training interventions will maintain global clinical impression scores, as defined by the Clinical Dementia Rating (CDR) scale, relative to the sham control condition.

4. PRT exercise will preferentially decrease inflammatory markers, insulin resistance, and central adiposity and increase fitness (strength and aerobic capacity), muscle mass, and functional mobility, compared to either cognitive or sham control condition.

5. Cognitive and physical training will produce positive effects on psychological health and quality of life above and beyond the non-specific effects seen after sham control condition.

\section{Methods}

\section{Study Design and Setting}

The SMART trial is a longitudinal double-blind, sham training-controlled, randomized clinical trial adhering precisely to CONSORT guidelines http://www.consortstatement.org for the conduct and reporting of clinical trials, as extended to non-pharmacological interventions [27]. Ethical approval was obtained from the Sydney South West Area Health Service (HREC Ref.08/RPAH/ 106), University of Sydney Human Research Ethics (HREC: 06-2008/11094), University of New South Wales (HREC: 08152), and signed informed consent was obtained from all participants. Participants are from the greater Sydney metropolitan area, and the study is conducted at Cumberland Campus of the University of Sydney in Lidcombe NSW Australia. MRI scans are performed at the Clinical Research Imaging Centre in Randwick NSW Australia.

\section{Study Population and Eligibility Criteria}

Participants are community-dwelling persons aged 55 or above, with primary inclusion criteria being self-reported memory complaint, a Clinical Dementia Rating (CDR) [28] of $\leq 1.0$; Mini-Mental Status Examination (MMSE) [29] score of 23-29; and willing to have multiple cognitive, physical and imaging assessments over 18 months. Complete inclusion and exclusion criteria are listed in Table 1.

\section{Recruitment}

Participants are to be recruited from October 2008 until December 2011 from media publicity on state radio, advertisements in local newspapers and businesses, a mail campaign using the electoral roll, contact with participants from previous studies who provided consent for such contact, general practitioner lists, aged care and health service facilities, community programs for seniors and word of mouth.

\section{Sample size estimates}

Sample size estimates (alpha 0.05, beta 0.20) are based on planned comparisons for the main effects of PRT and $\mathrm{CT}$, as well as the effect of combined training vs. either intervention in isolation on our primary outcome: global cognitive function as assessed by ADAS-Cog. The assumptions are as follows: our meta-analyses [30] and review of published RCTs in older adults [15] reveal Effect Sizes (ES) for a range of cognitive outcomes of approximately 0.60 for cognitive training, 0.59 for aero$\mathrm{bic} /$ resistance training, and 0.53 for resistance training, compared to 0.15 for control groups. However, as we are enrolling a cohort with early cognitive impairment, we anticipate a decline of approximately this magnitude $(\mathrm{ES}=0.15)$ over 12 months in our sample, so that the sham control condition would merely offset that decline $(E S=0.0)$. Thus, we have conservatively powered the study to show an ES of 0.53 for the main effects of both $\mathrm{CT}$ and PRT vs. control (n rounded up to 30/group $\times 4$ $=120$ required for 4-cell factorial design).

The only two published studies of combined mental and physical training $[12,16]$ showed average ES $=0.94$ for combined training compared to mental training alone and $\mathrm{ES}=1.27$ for combined training compared to exercise training alone. Therefore, we have ample power $(99.7 \%)$ to find a difference of this magnitude between our combined training $(\mathrm{n}=30)$ and isolated training groups $(\mathrm{n}=30)$. Reported dropout from drug trials in MCI is $28 \%$ [31] however our experience in fully supervised training of older adults with frailty/chronic disease dropout averages $10-15 \%$ over 12 months. Therefore, we will inflate sample size needs for approximately $10 \%$ drop out rate to account for anticipated attrition ( $\mathrm{n}=$ 132), and we will recalculate these sample size needs in interim analysis after the first 50 participants have 


\section{Table 1 Inclusion and exclusion criteria for the SMART trial}

\begin{tabular}{|c|c|}
\hline Inclusion criteria & Exclusion criteria \\
\hline $\begin{array}{l}\text { Age } \geq 55 \\
\text { Competency in English sufficient for assessment and training } \\
\text { Community-dwelling } \\
\text { MMSE } \wedge 23-29 \\
\text { CDR^^ } \leq 1.0 \\
\text { TICS \# }<30 \\
\text { No unstable disease precluding planned exercise* } \\
\text { Absence of significant cognitive decline in } 5 \text { years } \\
\text { Absence of known organic or psychiatric condition affecting } \\
\text { cognition } \\
\text { Able to see and hear sufficiently to participate in planned } \\
\text { physical and computer-based cognitive training }\end{array}$ & $\begin{array}{l}\text { Unstable medical condition* } \\
\text { Participation in any cognitive training activity } \\
\text { Participation in > } 150 \text { min/wk of moderate or greater intensity planned exercise of } \\
\text { any kind } \\
\text { Rapidly progressive or terminal illness } \\
\text { Pre-existing diagnosis of dementia } \\
\text { Psychotic illness (DSM-IV)** } \\
\text { Degenerative neurological disorder } \\
\text { Diagnosis of stroke or TIA }{ }^{+} \text {within last } 12 \text { months, stroke with residual neurological } \\
\text { deficit, two or more strokes or TIAs at anytime, One stroke or TIA with residual } \\
\text { deficits that preclude participation. } \\
\text { TBI }{ }^{ \pm} \text {within past year, or with residual deficits that preclude participation. } \\
\text { Diagnosis of depression (DSM-IV) GDS }{ }^{++}>9 \text { or current treatment with antidepressant } \\
\text { medications, greater than } 3 \text { episodes of depression in the last } 5 \text { years ("episode": } \\
\text { requiring treatment), }>10 \text { episodes requiring treatment over lifetime, past suicide } \\
\text { attempts, current bipolar diagnosis and treatment, }>3 \text { past episodes requiring } \\
\text { treatment in last } 5 \text { years. } \\
\text { Current alcohol or drug abuse (DSM-IV) } \\
\text { Unrepaired abdominal or other known aneurysm } \\
\text { Myocardial infarction or cardiac surgery within past } 6 \text { months } \\
\text { NYHA Class IV CHF }{ }^{ \pm \pm} \\
\text {Unstable angina or uncontrolled malignant arrhythmias at rest or on exercise stress } \\
\text { testing } \\
\text { Recent retinal haemorrhage or detachment/proliferative retinopathy } \\
\text { Seizures (>2 in past } 12 \text { months) }\end{array}$ \\
\hline
\end{tabular}

\footnotetext{
* Examples of unstable conditions include uncontrolled arrhythmias, hypertension, hyperglycemia, symptomatic enlarging hernia, acute pulmonary embolism, deep venous thrombosis, recent or unstable fracture, inflammatory or traumatic joint injuries, etc. Such individuals may become eligible if medical or surgical treatment stabilizes their condition.

$\wedge$ MMSE Mini Mental Status Examination ${ }^{27}$

$\wedge \wedge$ CDR Clinical Dementia Rating ${ }^{26}$

"TICS Telephone Interview for Cognitive Status -Modified ${ }^{30}$

**DSM-IV Diagnostic and Statistical Manual of Mental Disorders $4^{\text {th }}$ edition

+ TIA Trans Ischemic Attack

${ }^{ \pm}$TBI Traumatic brain Injury

${ }^{++}$GDS Geriatric Depression Scale [49]

${ }^{ \pm \pm}$NYHA Class IV CHF New York Heart Association Class IV Class of Heart Failure indicating symptoms evident at rest with any physical activity increasing symptoms, precluding ability to complete physical activity and causing severe limitations.
}

completed 6 months intervention and revise ES and sample size needs if required.

\section{Screening procedure}

Potential participants undergo initial telephone interview and screening using the 13-item modified Telephone Interview for Cognitive Status (TICS-M) [32], inclusion score between 21-30/39 to exclude high cognitively functioning individuals. Health status and lifestyle behaviours are also assessed via telephone. Informants are interviewed using the Bayer-Activities of Daily Living (B-IADL) [26], Informant KATZ Index of ADL [33], and informant ratings of memory decline and concern. A subset of informants complete an in-person B-IADL form to validate the telephone version.

Participants provide signed informed consent prior to completing a series of in-person screening assessments. A flow of assessment procedures is presented in Figure 2. A structured clinical interview including psychiatric screening is completed by a neuropsychologist, and CDR score is calculated prior to physician and physical screening. If eligible after physician screening, the remainder of the baseline physical performance testing is completed, followed by baseline cognitive tests and MRI scan. If following screening a participant was excluded for low vitamin D, acute illness, or abnormal stress test or raised blood pressure, he or she may enter the study following appropriate treatment and medical review. Participants are randomised at the completion of all baseline assessments.

\section{Randomisation, concealment, and allocation}

A concealed, computer-generated sequence of randomly permuted blocks (block size $=8$ ), stratified by gender and age, is generated by a statistician not otherwise involved in the study (http://www.randomization.com, created by Dr Gerard E. Dallal, Tufts University). Randomization occurs at the completion of the entire baseline assessment. Where randomization occurs in person, assignments will be placed in sealed opaque envelopes and delivered to subjects by the recruitment officer with subjects designated to 6 months of cognitive training, progressive resistance training, combined cognitive and 


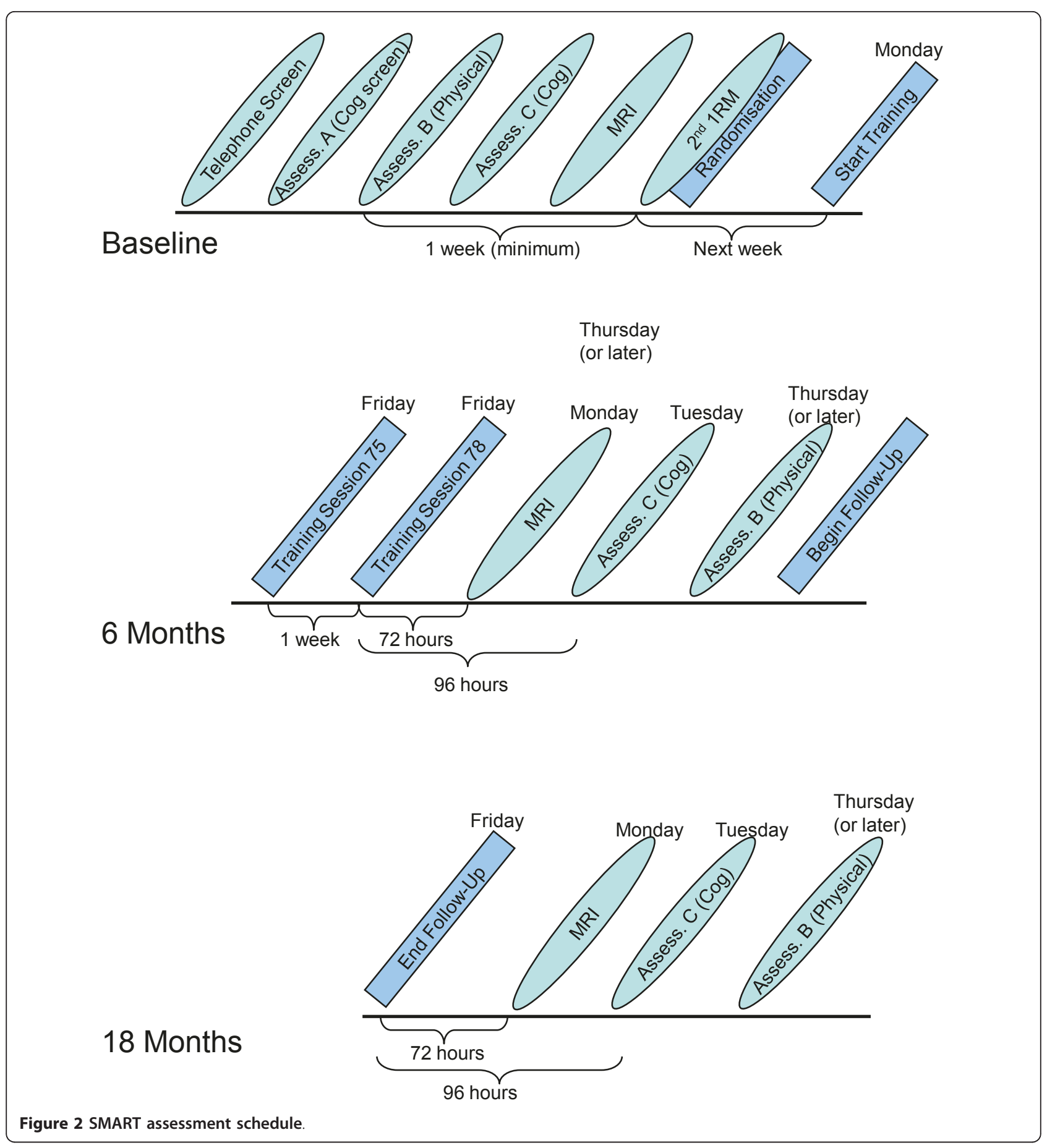

progressive resistance training, or stretching and videoquiz control group in a 1:1:1:1 ratio. Flow of subjects through the study to date is presented in Figure 3.

\section{Stratification}

Stratification by gender and age group $(55-74 ; 75+)$ is carried out, in anticipation of the greater prevalence of women in the targeted cohort, and potential age effects on adaptation to training.

\section{Blinding}

Subjects are informed that they will be randomly assigned to one of four treatment groups by the recruitment officer, and will be blinded to the investigators' 


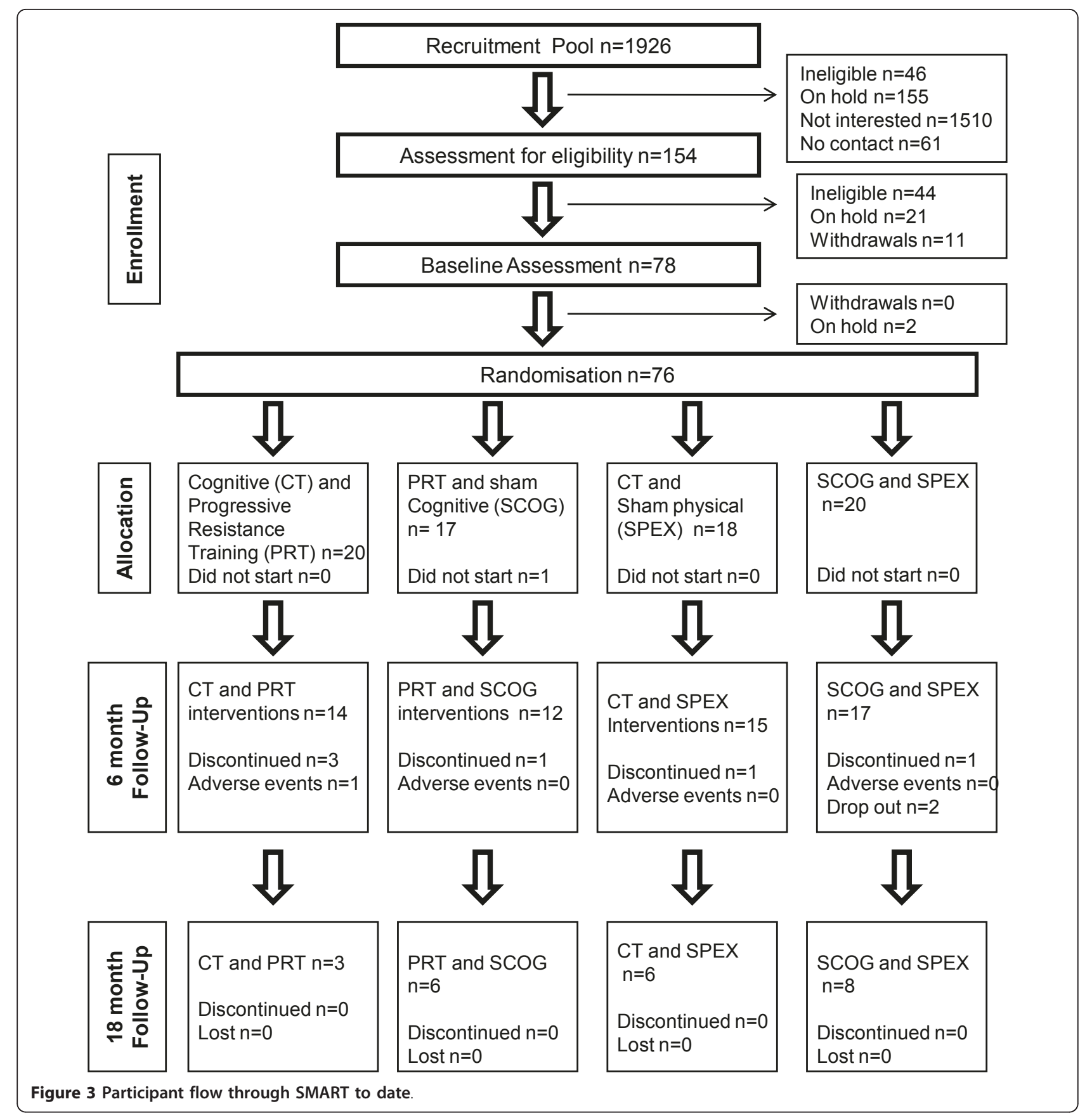

hypothesis as to which is the preferred intervention arm. All groups will have an equal volume and frequency of contact with trainers over the 18 months of the study. All primary and secondary outcomes will be obtained and analyzed by blinded assessors on different days to the training programs.

\section{Interventions}

All participants complete two group training sessions per week (total 26 weeks), under the supervision of trainers. Each session lasts 90 minutes and comprises approximately 45 minutes PRT or sham physical exercise (sham physical) and 45 minutes CT or sham cognitive exercise (sham CT). In order to take advantage of the enhanced attention and learning exhibited after an acute bout of exercise in both animal and human studies [34], but not enhance adaptation to sham cognitive training, PRT will proceed CT, and will follow sham CT.

Within each small group (maximum 10) participants follow the program tailored to their individual 
functioning level, with constant oversight by trainers. Make-up sessions are allowed for participants who miss CT and PRT sessions to achieve as close to $52(26 \times 2)$ sessions as possible within the 26 week intervention period. Each training group will have 1-2 trainers present at the session. The background of the trainers is in exercise physiology or physiotherapy, and the specific techniques of $\mathrm{CT}$ and PRT to be administered are learned from the investigators of this study (NG, MV, MFS).

Throughout the 18- month trial participants are provided with $\log$ books to document their social and recreational activities per day and are called weekly for telephone administration of a health status checklist. At the completion of the 6- month intervention participants are not given ongoing access to the training or advice as to what to do. Following assessments at 6 and 18 months participants receive a token reward (movie tickets or store voucher) for their participation.

\section{Cognitive Training Intervention (+ Sham physical)}

Cognitive training (CT) intervention involves computerbased multimodal and multi-domain exercises targeting memory, executive function, attention and speed of information processing. The training uses the COGPACK program [35], developed for neuro-rehabilitation and used in a previous research trial with MCI [36]. A total set of 14 exercises have been selected including six tasks of visual and verbal explicit memory ('Reading', 'Memory for names', 'Memory for shopping list', 'Memory for forms', 'Memory for route', 'Memory for traffic signs'), four tasks of executive function ('Anagrams', 'Sequence', 'Logic blocks', 'Logic') and four attention and speed tasks ('Reaction', 'Connect' UFOs' and 'Search'). The training schedule was pre programmed with 4 exercises being administered at each 45-minute training session. Training sessions are completed in a group setting with up to
10 computer work stations, and simple touch screens to avoid training difficulties in the computer-naïve.

\section{Progressive Resistance Training (+ Sham cognitive)}

Progressive resistance training (PRT) is supervised by experienced research assistants (exercise physiologists and physiotherapists) in a medically-supervised clinic (University of Sydney Health Sciences) at a ratio of 1 trainer for 45 subjects. The specifics of the high intensity training intervention are summarised in Table 2. Participants are progressed continuously throughout the 6-month intervention, guided by daily ratings of perceived exertion (1518 on the Borg Scale [37] and 1RM's every 3 weeks to maintain intensity at 3\% from 80 to $92 \%$ of current maximum capacity). Maximization of potential cognitiveenhancing effects of the PRT is supported by introduction of novel exercise after every 8 sessions and encouraging visualisation, counting out loud, and imagery of the muscle repetitions contracting during rest intervals.

\section{Combined CT and PRT}

This group will receive both the cognitive training intervention and progressive resistance training intervention, delivered on the same day within 90-minute sessions.

\section{Sham Cognitive and Sham Physical Exercise Control Group}

In this group, subjects will receive versions of cognitive and physical exercise that are considered to be ineffective with regards to the cognitive, neurological and physical outcomes of this trial. The total session length will be 90 minutes, and all training will be supervised in groups of up to 10 .

\section{Sham Cognitive}

Sham CT involves video exposure to a variety of general interest documentary topics, such as travel, culture, and history (National Geographic), and tailored to suit the audience and their expectation of training, are followed by a set of simple questions regarding the presented

Table 2 Progressive Resistance Training Methodology

\begin{tabular}{|c|c|c|c|c|c|}
\hline & Exercise & Equipment & Frequency & Volume & Intensity progression \\
\hline \multirow[t]{5}{*}{ Routine } & Seated Chest press & $\begin{array}{l}\text { Digital K400 Keiser pneumatic resistance } \\
\text { machines (Keiser Sports health } \\
\text { Equipments, Inc. Fresno, CA) }\end{array}$ & $\begin{array}{l}2 \text { sessions/ } \\
\text { wk }\end{array}$ & $\begin{array}{l}3 \text { sets of } \\
8 \text { per } \\
\text { session }\end{array}$ & $\begin{array}{l}80 \% \text { of the most recently measured } 1 \mathrm{RM} \\
\text { progressed each session } \mathrm{s} \text { tolerated using RPE* } \\
15-18 \text { (approximately } 3 \% \text { per session) }\end{array}$ \\
\hline & Seated leg press & & & & \\
\hline & Seated row & & & & \\
\hline & $\begin{array}{l}\text { Standing hip } \\
\text { abduction }\end{array}$ & & & & \\
\hline & Knee extension & & & & \\
\hline \multirow[t]{5}{*}{ Novel } & Lateral raise & Free weights (dumbbells) & $\begin{array}{l}4 \text { weeks or } \\
8 \text { sessions }\end{array}$ & $\begin{array}{l}3 \text { sets of } \\
8 \text { per } \\
\text { session }\end{array}$ & 15-18 RPE \\
\hline & Hip flexion & Keiser & & & \\
\hline & Calf raise & Keiser & & & \\
\hline & Hip extension & Keiser & & & \\
\hline & Bicep curls & Free weights (dumbbells) & & & \\
\hline
\end{tabular}


material. Previous CT trials used this type of active control condition [38] with minimal impact on cognitive outcomes.

\section{Sham Physical}

Sham physical exercise (Sham physical) will include stretching and seated calisthenics designed so as not to notably increase heart rate or aerobic capacity, improve balance, or enhance strength. No use of equipment and no progression will be included. This regime allows for maintenance of the double blind design as it is similar to what older adults anticipate receiving in senior group exercise classes. Furthermore, in contrast to aerobic activity, such a regimen has been shown recently to have no effects on brain volume in older adults [18].

\section{Adverse Events}

Monitoring of adverse events will be achieved by weekly questionnaire/interview- and proxy information will be obtained whenever necessary to minimize missing data. Adverse events will include any exacerbation of underlying disease, or new onset musculoskeletal, cardiovascular, or metabolic abnormality attributed directly to study protocols.

Table 3 Primary and secondary cognitive and functional outcome measures

\begin{tabular}{|c|c|c|}
\hline $\begin{array}{l}\text { Outcome } \\
\text { measure }\end{array}$ & Explanation & Description \\
\hline $\begin{array}{l}\text { Primary } \\
\text { Cognitive }\end{array}$ & $\begin{array}{l}\text { Alzheimer's Disease Assessment Scale } \\
\text { (ADAS-Cog) [25] }\end{array}$ & $\begin{array}{l}\text { This subscale of the ADAS, measures severity of cognitive dysfunction associated with } \\
\text { Alzheimer's disease and is widely used in pharmacological studies of dementia and MCl } \\
\text { [51]. The ADAS-Cog has excellent psychometric properties being valid and reliable, and } \\
\text { is endorsed as a standard outcome measure [26]. }\end{array}$ \\
\hline $\begin{array}{l}\text { Primary } \\
\text { Functional }\end{array}$ & $\begin{array}{l}\text { Bayer-Instrumental Activities of daily Living } \\
\text { (B-ADL) }[26,52]\end{array}$ & $\begin{array}{l}\text { The B-IADL initially developed for pharmaceutical clinical trials to assess deficits in the } \\
\text { activities of daily life in community-dwelling individuals with } \mathrm{MCl} \text { and response to } \\
\text { pharmacological agents [26], is a } 25 \text {-item informant or proxy questionnaire. }\end{array}$ \\
\hline \multirow[t]{14}{*}{$\begin{array}{l}\text { Secondary } \\
\text { Cognitive }\end{array}$} & Mini-Mental State Examination (MMSE)[29] & $\begin{array}{l}\text { Internationally known brief measure to screen for cognitive impairment [41], with valid } \\
\text { and reliable quantitative assessment of severity of cognitive impairment, and is sensitive } \\
\text { to changes in cognitive function over time [53]. }\end{array}$ \\
\hline & GP-Cog $[54]$ & $\begin{array}{l}\text { Six item self report scale identifying whether patients have greater difficulty functioning } \\
\text { in } 6 \text { areas of daily life compared to their level of functioning 5-10 years earlier. }\end{array}$ \\
\hline & Clinical Dementia Rating (CDR) [28] & $\begin{array}{l}\text { A commonly used clinical tool for the global assessment of dementia severity, is } \\
\text { completed by a clinician after synthesizing information obtained from the patient, } \\
\text { informants and any other sources [28]. }\end{array}$ \\
\hline & Subjective Memory Complaint (SMC) & $\begin{array}{l}\text { Eight questions were developed to measure SMC including type of memory difficulty, } \\
\text { concern level, duration, comparison to peers, and reported by informant, meeting } \\
\text { criteria for the assessment of SMC [55]. }\end{array}$ \\
\hline & Life Experience Questionnaire (LEQ)[19] & $\begin{array}{l}\text { Questionnaire is a self report questionnaire examining the amount and quality of mental } \\
\text { activity a person has engaged in over their life time [19]. }\end{array}$ \\
\hline & Matrices & $\begin{array}{l}\text { Matrices, a perceptual subtest of the Wechsler Adult Intelligence Scale-III (WAIS-III) } \\
\text { assesses executive functions and requires visual perception, organization, and synthesis } \\
\text { of visual spatial information [56]. }\end{array}$ \\
\hline & Similarities & $\begin{array}{l}\text { This verbal subtest from the WAIS-III is used to measure verbal conception formation } \\
\text { and abstraction [56]. }\end{array}$ \\
\hline & Trail Making Test (TMT)[40] A and B & $\begin{array}{l}\text { Trials } A \text { and } B \text { test speed of attention, sequencing and visual search, and includes a } \\
\text { motor response component, whilst B also assesses mental flexibility, an executive } \\
\text { function [57]. }\end{array}$ \\
\hline & Logical Memory & $\begin{array}{l}\text { The Logical Memory subtest of the Wechsler Memory Scale } 3^{\text {rd }} \text { edition (WMS-III) is used } \\
\text { to measure both immediate and delayed memory for verbal information. }\end{array}$ \\
\hline & Benton Visual Retention Test (BVRT)[42] & $\begin{array}{l}\text { This widely used visual memory test assesses visual perception and visual constructive } \\
\text { abilities as participants are required to draw from memory simple designs [41]. }\end{array}$ \\
\hline & Symbol Digit Modalities Test (SDMT) & $\begin{array}{l}\text { SDMT, first published in } 1973 \text { by Aaron Smith and subsequently revised in 1982[41] } \\
\text { measures divided attention, visual scanning, tracking, and motor speed. It uses a } \\
\text { substitution format presenting symbols with matching numbers, and participants are } \\
\text { required to name the numbers corresponding to each given symbol. }\end{array}$ \\
\hline & Category Fluency & $\begin{array}{l}\text { Category Verbal Fluency measures verbal production of animal names from semantic } \\
\text { memory [58]. }\end{array}$ \\
\hline & $\begin{array}{l}\text { Controlled Oral Word Association Test } \\
\text { (COWAT) }\end{array}$ & $\begin{array}{l}\text { COWAT is a language based task assesses association fluency, and is often used as a } \\
\text { measure of executive functioning. The most commonly used letters are F. A. S. or C. F. } \\
\text { and L. based upon word prevalence rates [58]. }\end{array}$ \\
\hline & $\begin{array}{l}\text { Memory Awareness Rating Scale-Memory } \\
\text { Functioning (MARS-MF) [43] }\end{array}$ & $\begin{array}{l}\text { The MARS-MF is an } 11 \text { item self report rating scale of everyday memory functioning. } \\
\text { Ratings are made on a } 0-4 \text { scale where } 0=\text { never and } 4=\text { always, and is usually } \\
\text { administered in an interview format [43]. }\end{array}$ \\
\hline
\end{tabular}


Specific adverse events that will be routinely monitored include: falls, cardiac events during physical testing and exercise training (angina, arrhythmias, blood pressure excursions, clinically significant ECG changes); fatigue and muscle soreness or musculoskeletal injury after resistance or sham physical training; anxiety during MRI scan or cognitive or sham cognitive training; pain or injury related to movement of ferromagnetic devices, implants, shrapnel during MRI scan; and pain, bruising, or infection at the venipuncture site. In addition, subjects will be asked to report all changes in medication, health care professional visits, new diagnoses, acute illnesses, or any new symptoms.

\section{Outcome Measures}

All outcome measures (see Tables 3, 4, 5, 6 and 7) will be administered by blinded assessors at baseline, 6 months and at 18 months follow-up. Each test is chosen because of excellent psychometric properties and minimal sensitivity to practice effects. Cognitive testing takes place in a fed state (after breakfast), and before any physical testing on that day to standardize known effects of fasting and acute exercise on cognitive performance.

\section{Primary outcomes}

Cognitive function is measured via the Alzheimer's Disease Assessment Scale-Cognitive (ADAS-Cog) [25], and capacity to perform daily tasks by the Bayer-Activities of Daily Living (B-IADL) [26] which has been found to differentiate between normal ageing and mild to moderate dementia [39].

\section{Secondary Outcomes}

Cognitive function Global cognitive function is assessed via the Clinical Dementia Rating scale (CDR) [28], and
Mini-Mental Status Examination (MMSE) [29]. Specific cognitive functions are assessed by Trail Making Test A and B [40], Matrices and Similarities subtests of the Wechsler Adult Intelligence Scale $3^{\text {rd }}$ Edition (WAISIII), Symbol Digit Modalities Test (SDMT) [41], Logical Memory I and II subtests of the Wechsler Memory Scale $3^{\text {rd }}$ Edition (WMS-III), Benton Visual Retention Test-Revised $5^{\text {th }}$ Edition (BVRT-R) [42] and verbal fluency (Controlled oral words association test, and animal names). Subjective perception of memory capacity is assessed by the Memory Functioning Scale of the Memory Awareness Rating Scale (MARS-MFS) [43]. Cognitive domain scores will be calculated on the basis of sum of z-scores of index tests, referenced to wholegroup baseline results.

Psychosocial and quality of life Psycho-social wellbeing and quality of life are assessed via the Life Satisfaction Scale (LSS) [44], Physical and Mental Health Short-36 (SF-36>)[45], Quality of Life Scales (QOLS) [46], Scale of Psychological Well Being (SPWB) [47], Depression, Anxiety, Stress Scales (DASS) [48], the Geriatric Depression Scale (GDS) [49], and Duke Social Support (DSS) [50].

Physical status and level of functional capacity Physical status and exercise capacity are assessed across seven domains: body composition; cardio vascular profile; exercise capacity; functional performance; nutritional status; health status; and inflammatory and anabolic profile, with measures described in Table 4.

Neuroimaging MRI data are acquired at baseline, 6 months follow up and 18 months follow up, using a 3.0Tesla Philips Achieva System (see Table 7). For each

Table 4 Secondary outcome measures continued: Psycho-social status

\begin{tabular}{|c|c|c|}
\hline $\begin{array}{l}\text { Outcome } \\
\text { Measure }\end{array}$ & Name of scale & Description \\
\hline \multirow[t]{4}{*}{$\begin{array}{l}\text { Psycho- } \\
\text { social }\end{array}$} & $\begin{array}{l}\text { Geriatric Depression Scale (GDS) } \\
\text { 15-items [49] }\end{array}$ & $\begin{array}{l}\text { The GDS is used to assess an older person's level of depression with simple yes/no response set } \\
\text { [59], and the fifteen item screening test has been reported to be satisfactory [49]. }\end{array}$ \\
\hline & $\begin{array}{l}\text { Depression Anxiety and Stress } \\
\text { Scale 21(DASS) [60] }\end{array}$ & $\begin{array}{l}\text { 21-item self-report measure of severity of depression, anxiety, and stress psychological symptoms. } \\
\text { Overall Distress can be calculated by summing each of the sub-scale scores with possible scores } \\
\text { ranging from 0-63, with higher scores indicating higher distress [48]. }\end{array}$ \\
\hline & $\begin{array}{l}\text { Scale of Psychological Wellbeing } \\
\text { (SPWB) [47] }\end{array}$ & $\begin{array}{l}\text { The SPWB measures well-being and psychological functioning includes six subscales: autonomy; } \\
\text { environmental mastery; personal growth; positive relations with others; purpose in life; and self- } \\
\text { acceptance [47]. Participants are required to rate agreement on a six point agreement scale, with } \\
\text { higher scores indicating greater wellbeing. }\end{array}$ \\
\hline & Duke Social Support (DSS)[50] & $\begin{array}{l}\text { The DSS is used to assess perceived adequacy and size of social support network on a } 3 \text { point scale } \\
\text { with higher total scores reflecting higher levels of social support [50]. }\end{array}$ \\
\hline \multirow[t]{3}{*}{$\begin{array}{l}\text { Quality of } \\
\text { life }\end{array}$} & Life satisfaction Scale (LSS)[44] & $\begin{array}{l}\text { This single item } 7 \text { point delighted-terrible rating scale provides a gestalt measure of life satisfaction, } \\
\text { and can yield reliable and valid data [61]. }\end{array}$ \\
\hline & $\begin{array}{l}\text { Physical and Mental Health } \\
\text { Summary Scales (SF36) }\end{array}$ & $\begin{array}{l}\text { The Physical \& Mental Health Summary Scales include eight generic health concepts, selected from } \\
40 \text { included in the Medical Outcomes Study (MOS), and MOS researchers selected and adapted } \\
\text { questionnaire items and developed new measures for a 149-item Functioning and Well-Being } \\
\text { Profile [62] the source for SF-36 }{ }^{\mathbb{R}} \text { items. }\end{array}$ \\
\hline & Quality of Life Scales (QoLS)[46] & $\begin{array}{l}\text { This } 16 \text { item } 7 \text { Likert type delighted-terrible self report scale measures satisfaction with five } \\
\text { conceptual aspects of life notably material and physical wellbeing; relationships with other people, } \\
\text { social, community and civic activities; personal development and fulfilment; and recreation [46]. }\end{array}$ \\
\hline
\end{tabular}


Table 5 Secondary outcome measures continued: physical health and functional status

\begin{tabular}{|c|c|c|}
\hline $\begin{array}{l}\text { Outcome } \\
\text { Measure }\end{array}$ & Explanation & Description \\
\hline \multirow[t]{2}{*}{$\begin{array}{l}\text { Body } \\
\text { composition }\end{array}$} & Anthropometrics & $\begin{array}{l}\text { Standing height body weight, waist circumference are obtained in triplicate after } 12 \text { hour fasting and } \\
\text { body mass index (BMI)) is calculated as fasting body weight (weight } \mathrm{kg} / \text { height } \mathrm{m}^{2} \text { ). }\end{array}$ \\
\hline & $\begin{array}{l}\text { Bioelectrical Impedance } \\
\text { Analysis (BIA) }\end{array}$ & $\begin{array}{l}\text { Whole-body skeletal muscle mass }(\mathrm{kg})(\mathrm{SMM})^{*} \text { and fat free mass }(\mathrm{kg})(\mathrm{FFM}){ }^{* *} \text { were calculated using the } \\
\text { average resistance and reactance values of three sequential BIA measures using the BIA Analyser (RLJ } \\
\text { Prizum, S/N: B10875E, Mode; BIA-101S). }\end{array}$ \\
\hline \multirow[t]{3}{*}{$\begin{array}{l}\text { Cardio- } \\
\text { vascular }\end{array}$} & Pulse Wave Analysis & $\begin{array}{l}\text { Pulse Wave Velocity (PW) Pulse Wave Analysis (PWA) Heart Rate Variability (HRV) is determined using } \\
\text { the SphygmoCor Unit and SphygmoCor software. }\end{array}$ \\
\hline & Ankle Brachial Index (ABI) & Clinton MI) Ankle-brachial index (mean of dorsalis pedis and posterior tibialis/brachial BP in both arms). \\
\hline & Blood Pressure (BP) & $\begin{array}{l}\text { Orthostatic hypotension }(\mathrm{OH}) \text { Orthostatic Blood Pressure Measurement is taken in a fasted state and } \\
\text { after rising from a five minute rest in supine position. Twenty-four hour ambulatory BP monitoring, } \\
\text { awake and nocturnal means and circadian rhythm are also obtained. }\end{array}$ \\
\hline \multirow[t]{3}{*}{$\begin{array}{l}\text { Exercise } \\
\text { Capacity }\end{array}$} & $\begin{array}{l}\text { Muscle strength and } \\
\text { endurance }\end{array}$ & $\begin{array}{l}\text { Maximal strength measurement will be obtained using the digital K400 Keiser pneumatic resistance } \\
\text { machines (Keiser Sports health Equipments, Inc. Fresno, CA). See table } 7 \text { for details. }\end{array}$ \\
\hline & $\begin{array}{l}6 \text { minute walk distance } \\
\text { (6MWD) [63] }\end{array}$ & $\begin{array}{l}\text { Walking endurance was assessed using the six minute walk test which is a proxy for overall } \\
\text { cardiovascular endurance capacity (aerobic capacity) and in the elderly subject it may be determined by } \\
\text { muscle strength and endurance, balance, orthopaedic or neurologic abnormalities, and other problems } \\
\text { [63]. }\end{array}$ \\
\hline & Aerobic Capacity & Maximal exercise capacity assessed on treadmill walking test (stress test). \\
\hline \multirow[t]{7}{*}{$\begin{array}{l}\text { Physical } \\
\text { performance }\end{array}$} & $\begin{array}{l}\text { Gait speed habitual and } \\
\text { fast }\end{array}$ & $\begin{array}{l}\text { Habitual and maximal gait velocities is assessed for } 2 \mathrm{~m} \text { (Ultra-timer: Raymar, Oxfordshire, UK) with the } \\
\text { average of two times taken as habitual }(\mathrm{CV}=8.7 \%) \text { and maximal }(\mathrm{CV}=7.6 \%) \text { gait velocity respectively. }\end{array}$ \\
\hline & Gait analysis (Gait Logger) & $\begin{array}{l}\text { Participants walk two walks of } 2 \text { minute duration and data is recorded using the gait logger Minion } \\
\text { EGaitLogger and downloaded }\end{array}$ \\
\hline & $\begin{array}{l}\text { Isometric handgrip } \\
\text { strength }\end{array}$ & $\begin{array}{l}\text { Isometric handgrip strength of the non dominant hand is assessed using a JAMAR handgrip } \\
\text { dynamometer (Sammons Preston, Bolingbrook, IL) }\end{array}$ \\
\hline & Chair stand [64] & $\begin{array}{l}\text { This test is used as a proxy for lower extremity power, or the ability to generate high forces rapidly, } \\
\text { with participants primarily utilising the hip extensor and knee extensor muscle groups [64]. }\end{array}$ \\
\hline & Static Balance & $\begin{array}{l}\text { Static balance is assessed up to } 15 \text { seconds in five different positions (feet apart in parallel stance, feet } \\
\text { together in parallel stance, half tandem stance, tandem stance, and one legged stance), without the use } \\
\text { of assistive device with eyes open. Total static balance is calculated by summing the time recorded for } \\
\text { each of the six stances[65]. }\end{array}$ \\
\hline & Tandem walk & $\begin{array}{l}\text { Subjects complete a } 3 \text { meter forward tandem walk along a marked course with and without a cognitive } \\
\text { distracter task (verbal fluency) }\end{array}$ \\
\hline & Stair climb & $\begin{array}{l}\text { The purpose of this test is to climb stairs as rapidly as possible to enable the calculation of Power } \\
\text { (Watts). Power is calculated from the formula: } P(\text { watts })=(M \times D) \times 9.8 / t \text { Where: } M=\text { Body mass }(\mathrm{kg}) \text {, } D \\
=\text { Vertical distance }(\mathrm{m}), \mathrm{t}=\text { Time }(\mathrm{s}) \text { and, } \mathrm{D}=\text { vertical height of the staircase }=\text { height of } 1 \text { step in } \\
\text { meters } \times \text { number of steps (if they are all the same height). }\end{array}$ \\
\hline
\end{tabular}

*Skeletal muscle mass $(\mathrm{SMM})=0.401$ (height in $\mathrm{cm}^{2} /$ resistance in ohms)+3.825 (sex: male $=1$; female $\left.=0\right)+$ age in years $(-0.071)+5.102$ [66]

${ }^{*}$ Fat-free mass $(F F M)=-4.03+0.734$ (height in $\mathrm{cm}^{2} /$ resistance in ohms) +0.116 (body weight in $\left.\mathrm{kg}\right)+0.096($ reactance in ohms) $+0.984($ sex: $\mathrm{male}=1$; female $=$ 0)[67]

time point, brain structure is assessed using a T1weighted whole brain scan (sequence: T1TFE; TR/TE: $6.39 / 2.9 \mathrm{~ms}$; slice thickness $1.0 \mathrm{~mm}$ without gap; field of view: $256 \times 256$; resolution $1 \times 1 \mathrm{~mm})$ and a T2 FLAIR scan (sequence: TIR; resolution: $0.488 \times 0.488 \times 3.5$ $\mathrm{mm}$; TR/TE $=10,000 / 110 \mathrm{~ms}) .{ }^{1} \mathrm{H}$-MRS follows in two volumes of interest: left hippocampus $(20 \mathrm{~mm} \mathrm{M} / \mathrm{L}, 15$ $\mathrm{mm} \mathrm{D} / \mathrm{V}, 30 \mathrm{~mm} \mathrm{~A} / \mathrm{P}$, oriented along the hippocampus) and posterior cingulate grey matter $(20 \mathrm{~mm} \mathrm{M} / \mathrm{L}, 20$ $\mathrm{mm} \mathrm{D} / \mathrm{V}, 20 \mathrm{~mm} \mathrm{~A} / \mathrm{P}$ ) using the PRESS sequence (TE/ $\mathrm{TR}=30 / 2000 \mathrm{~ms}, 1024$ points, 256 averages). Finally, a resting state functional MRI is conducted using T2* echo-planar BOLD sequence $(\mathrm{TR} / \mathrm{TE}=2000 / 30 \mathrm{~ms}, 200$ volumes) with the subject's eyes closed.

\section{Covariates}

Covariates specified $a$ priori are age, gender, educational history, occupational history, burden of chronic disease (medications and diagnoses), nutritional supplements, history of weight loss in past year and habitual physical activity level.

\section{Statistical Analysis}

We will use an intention to treat (ITT) analytic strategy as our primary analytic treatment of the data. However, we acknowledge the potential bias of any method of imputation [last observation carried forward (LOCF), mean of group, expectation maximization algorithm (EM)] or restriction to observed cases (complete case analysis). 
Table 6 Secondary outcome measures continued: Health status

\begin{tabular}{|c|c|c|}
\hline Outcome measure & Explanation & Description \\
\hline \multirow[t]{3}{*}{ Health Status } & Habitual Physical Activity level & $\begin{array}{l}\text { Daily physical activity, sedentary behaviour and sleep quality and } \\
\text { quantity are measured with two Actigraph monitors worn for seven } \\
\text { days. The actigraph on the waist measures physical activity and the } \\
\text { wrist sleep quality, with data analysed using the ActilifeGTIM (version } \\
\text { 2.2.3) and ActiWebClient (version 4.2.2) programs. }\end{array}$ \\
\hline & Cortisol & $\begin{array}{l}\text { Five saliva cortisol samples will be collected using the Salivette } \\
\text { (Sarstedt Aktiengessllschaft and Company; Kirschbaum \& } \\
\text { Hellhammer, 1994) and according to manufacturer instructions. A } \\
\text { control 'resting' "Pre" and "Post" samples will be taken before } \\
\text { exposure to each 'stressor' condition fasting and upon awakening } \\
\text { and } 30 \text { minute rest, and a prior to stressor and immediately after the } \\
\text { termination of the stressor condition. The cognitive 'stressor' } \\
\text { condition is Alzheimer's Disease Assessment Scale (ADAS-Cog) } \\
\text { assessment during screening and at } 6 \text { months assessment } \\
\text { (approximately } 45 \text { min), the physical stressor is the second exposure } \\
\text { to a set of maximal strength testing (1RM testing) at baseline and } 6 \\
\text { mo. }\end{array}$ \\
\hline & Medical History & $\begin{array}{l}\text { Physician complete medical history and physical and neurological } \\
\text { examination. }\end{array}$ \\
\hline $\begin{array}{l}\text { Inflammatory/Anabolic/ } \\
\text { Deoxyribo-Nucleic Acid } \\
\text { (DNA) profile }\end{array}$ & $\begin{array}{l}\text { Serum samples for nutritional, biochemical and } \\
\text { hormonal factors, pro- and anti-inflammatory } \\
\text { cytokines }\end{array}$ & $\begin{array}{l}\text { A venous blood draw is taken after a } 12 \text { hour fast for B12, folate, } \\
\text { Thyroid Stimulating Hormone (TSH), insulin, glucose (with calculation } \\
\text { of insulin sensitivity and beta-cell function using the HOMA2 } \\
\text { Computer Model), Liver Function Tests (LFT), cholesterol (Total, High } \\
\text { Density Lipoprotein, Low Density Lipoprotein, Triglycerides), Full } \\
\text { blood count, creatinine, albumin, homocysteine, and } 25-O H \text { vitamin } \\
\text { D level, and a second sample taken to measure specialist markers of } \\
\text { inflammation: high sensitivity C-reactive protein (hs-CRP), cytokines } \\
\text { InterLeukin (IL)-1b, IL-6, IL-8, IL-10, IL-12p70, IL-18 and Tumor } \\
\text { Necrosis Factor- proteins (TNF-proteins), as well as Brain Derived } \\
\text { Neurotrophic Factor (BDNF), Insulin Growth Factor-1 (IGF-1). At } \\
\text { Baseline only a blood draw is taken for genetic Testing for } \\
\text { Apolipoprotein allele } 4 \text { (APOE 4). }\end{array}$ \\
\hline
\end{tabular}

Therefore, we will make all attempts to retrieve data from dropouts by obtaining final measures regardless of intervention participation or compliance, and will use the EM method for data missing at random. In addition, we will compare characteristics of dropouts to completers and perform secondary sensitivity analyses (completers, and per-protocol analyses) to examine potential for dropouts and imputation to bias the results.

Mixed modelling of 6-and 18-month outcomes, adjusted for baseline values and any potential confounders identified will be constructed to test our primary and secondary hypotheses. We will test for main effects of CT and PRT, as well as for the interaction term (CT $\times$ PRT) to identify isolated and combined training arm significance and effects sizes. Relationships of interest and risk factors for changes in cognitive function and other secondary outcomes will be analysed with simple and multivariate linear and logistic regression models as appropriate. Weighted mean differences, 95\% Confidence Intervals and Effect Sizes will be calculated for all outcomes, and clinical meaningfulness will be assessed in light of available data on the expected annual rates of change in this cohort for all known primary and secondary outcome variables.

\section{Results}

We originally estimated the need for a sample size $10 \%$ larger than our expected effect size required $(n=132)$. With our retention rate of $>90 \%$ to date our recruitment target remains appropriate $120 / .90=133$. Thus, we have recruited $80 / 133,60 \%$ of our planned cohort to date. Compliance with training sessions to date has been high for all groups with median compliance ranging from $78.44 \%$ for sham physical/CT to $100 \%$ for PRT/CT. Furthermore there has been one adverse event reported thus far (one rotator cuff injury managed conservatively) in PRT group, and no adverse events during assessments, CT, or sham interventions.

\section{Discussion and conclusions}

Recruitment of subjects has been challenging, with less than $4 \%$ of contacts recruited, and 12 telephone screening interviews required for each subject enrolled. However, the most common reasons for ineligibility have been lack of cognitive impairment, or being too physically active, rather than medical exclusions, attesting to the potential generalizability of this volunteer sample to typical older adults with multiple stable chronic illnesses and mild cognitive impairment. 
Table 7 Secondary outcomes continued: neuroimaging

\begin{tabular}{|c|c|c|}
\hline Outcome & Measure & Description \\
\hline \multirow[t]{6}{*}{$\begin{array}{l}\text { Structural MRI: T1- } \\
\text { weighted } \\
\text { Whole Brain Measures }\end{array}$} & 1. Voxel Based Morphometry & $\begin{array}{l}\text { A combination of different software packages will be used for automated and semi- } \\
\text { automated computational neuroanatomical analyses, in addition to expert manual tracing } \\
\text { of hippocampus and entorhinal cortex. }\end{array}$ \\
\hline & 2. Cortical thickness & \\
\hline & 3. Whole brain volume & \\
\hline & 4. GM volume & \\
\hline & 5. WM volume & \\
\hline & 6. CSF volume & \\
\hline \multirow[t]{2}{*}{ Regional Measures } & $\begin{array}{l}\text { 1. Automated regional cortical } \\
\text { volume measures }\end{array}$ & \\
\hline & $\begin{array}{l}\text { 2. Manually traced subcortical } \\
\text { volumes }\end{array}$ & \\
\hline FLAIR-weighted MRI & $\begin{array}{l}\text { White matter hyperintensity } \\
\text { volume }\end{array}$ & Automated measure of white matter disease load \\
\hline \multirow{4}{*}{$\begin{array}{l}\text { Magnetic Resonance } \\
\text { Spectroscopy (MRS) } \\
\text { Relative measures of : }\end{array}$} & 1. N-acetylaspartate (NAA) & $\begin{array}{l}\text { Measures of different brain metabolites using MR spectroscopy in the hippocampus and } \\
\text { posterior cingulate grey matter. }\end{array}$ \\
\hline & 2. Cholines & \\
\hline & 3. Myo-inositol & \\
\hline & 4. Creatine+Phosphocreatine & \\
\hline \multirow[t]{5}{*}{$\begin{array}{l}\text { Resting State functional } \\
\text { MRI }\end{array}$} & $\begin{array}{l}\text { 1. Bilateral hippocampal } \\
\text { connectivity }\end{array}$ & $\begin{array}{l}\text { Seed-based correlational analysis and Independent Component Analysis will be used to } \\
\text { characterise individuals' resting state BOLD time series. }\end{array}$ \\
\hline & $\begin{array}{l}\text { 2. Hippocampus functional } \\
\text { connectivity map }\end{array}$ & \\
\hline & $\begin{array}{l}\text { 3. Posterior cingulate } \\
\text { functional connectivity map }\end{array}$ & \\
\hline & $\begin{array}{l}\text { 4. Default Mode Network } \\
\text { (DMN) }\end{array}$ & \\
\hline & 5. DMN-anticorrelations & \\
\hline
\end{tabular}

Our primary outcomes of global cognitive status and functional independence are anticipated in 2012. This information will provide novel and robust evidence for the efficacy of cognitive and strength training on cognition and functional status in at risk older adults. This study conforms to all CONSORT criteria for the reporting of RCTs, making it relatively unique in the field to date. Furthermore, the SMART trial will provide valuable information on the persistence of training benefits after cessation of training at 18 months. Recording participant social and recreational activities will also enable SMART to examine the impact of training post intervention on leisure activity, and control against potential confounding effects of participants independently pursuing physical exercise and mental activities.

Our secondary outcomes will enable the first comprehensive investigation of the relative and combined benefits of physical and cognitive training on brain morphology and function, anxiety and depressive symptoms, self-efficacy, quality of life, body composition, cardiovascular risk profile, aerobic and musculoskeletal fitness, and metabolic health. These outcomes will not only provide evidence of the potentially broad benefits of the SMART interventions in this cohort, but also clarify the hypothesized mechanisms contributing to any observed cognitive outcomes.

In summary, SMART will test a non-pharmacological preventative intervention that targets older adults at high risk of cognitive decline. By implementing a regime of physical and mental exercise, we aim to empower the individual, contribute to their physical, cognitive and psychological health, and ultimately improve quality of life.

\section{Acknowledgements}

This study is funded by the Dementia Research Grant (no.512672) from 2008. Additional funding for a research assistant position was sourced from the NHMRC program support, and the project is supported by the University of Sydney and University of New South Wales. MV is supported by a University of New South Wales Vice Chancellor's Fellowship. Donations for participant rewards were received from Gregory and Carr Funerals. We would also like to thank Nathan deVos for designing figure 1 for us, and all the participants who devoted their time to this project.

\section{Author details}

${ }^{1}$ School of Psychiatry, University of New South Wales, Randwick NSW 2031, Australia. ${ }^{2}$ Brain and Aging Research Program, University of New South Wales, Randwick NSW 2031, Australia. ${ }^{3}$ Regenerative Neuroscience Group, School of Psychiatry, University of New South Wales, Randwick NSW 2031, Australia. ${ }^{4}$ Neuropsychiatric Institute, Prince of Wales Hospital, Randwick NSW 
2031, Australia. ${ }^{5}$ Balmain Hospital, Balmain NSW 2041, Australia. ${ }^{6}$ Royal Prince Alfred Hospital, Camperdown NSW 2050, Australia. 'Discipline of Psychiatry, School of Medicine, University of Adelaide, Adelaide SA 5005, Australia. ${ }^{8}$ Primary Dementia Collaborative Research Centre, University of New South Wales, Randwick NSW 2031, Australia. ${ }^{9}$ Exercise Health and Performance Faculty Research Group, Sydney Medical School, The University of Sydney, Lidcombe NSW 2141, Australia. ${ }^{10}$ Hebrew Senior Life, Boston, MA, and Jean Mayer USDA Human Nutrition Research Center on Aging at Tufts University, Boston 02130, MA, USA.

\section{Authors' contributions}

All authors critically reviewed the manuscript. NG manuscript draft; HB, PS, MV, MFS, BTB, NG, MB design of study; MFS, HB, PS, BTB, MV, study conception; NJ subject recruitment, telephone screening and scheduling; NG, MFS eligibility screening; NG cognitive assessment; MB, GW, DW, NJ physical assessment; MFS, YW, NJ database and protocol management; MB, $N F, N J$, GW training; MV, CS fMRI; NJ, MB, DW, GW, NG data management and analysis.

\section{Competing interests}

The authors have no conflicts of interest. MV has previously received honoraria for speaking at Pfizer sponsored events. $\mathrm{HB}$ is an investigator for Pfizer, Novartis, Janssen, Lundbeck, Lilly, a sponsored speaker for Pfizer, Novartis, Janssen, and on advisory Boards for Pfizer, Novartis, Janssen, and Lundbeck. NG holds shares in HeadStrong Brain LLC New York although no dividends, gifts or royalties have ever been received and no work has been conducted for the company since 2007.

Received: 11 February 2011 Accepted: 21 April 2011

Published: 21 April 2011

\section{References}

1. Andrieu S, Coley N, Aisen P, Carrillo MC, Dekosky S, Durga J, Fillit H, Frisoni GB, Froelich L, Gauthier S, Jones R, Jönsson L, Khachaturian Z, Morris JC, Orgogozo JM, Ousset PJ, Robert P, Salmon E, Sampaio C, Verhey F, Wilcock G, Vellas B: Methodological issues in primary prevention trials for neurodegenerative dementia. Journal of Alzheimer's Disease 2009, 16(2):235-270.

2. Katzman R: Education and the prevalence of dementia and Alzheimer's disease. Neurology 1993, 43:13-20.

3. Kaduszkiewicz $H$, Zimmerman T, Beck-Bornholdt $H$, van der Bussche $H$ : Cholinesterase inhibitors for patients with Alzheimer's disease: systematic review of randomised clinical trials. BMJ 2005, 331:321-327.

4. Wilson R, Mendes de Leon C, Barnes L: Participation in cognitive stimulating activities and risk of incident Alzheimer's disease. JAMA 2002, 287:742-748.

5. Valenzuela MJ, Sachdev P: Brain reserve and dementia: A systematic review. Psychological Medicine 2006, 36(4):441-454.

6. Verghese J, Lipton R, Katz M, Hall C, Derby C, Kuslansky G: Leisure activities and the risk of dementia in the elderly. New England Journal of Medicine 2003, 348:2508-2524.

7. Cotman CW, Berchtold N, Christie L: Exercise builds brain health; key roles of growth factor cascades and inflammation. Trends in Neurosciences 2007, 30(9):464-472.

8. Heyn PC, Johnson KE, Kramer AF: Endurance and strength training outcomes on cognitively impaired and cognitively intact older adults: A meta-analysis. Journal of Nutrition, Health and Aging 2008, 12(6):401-409.

9. Larson EB: Exercise is associated with reduced risk for incident dementia amoung persons 65 years of age and older. Annals of International Medicine 2006, 144:73-81.

10. Ball $K$, Berch $D$, Helmers $K$ : Effect of cognitive training interventions with older adults- a randomised control trial. JAMA 2002, 288:2271-2281.

11. Mahncke HW, Connor B, Appelmann J, Ahsanuddin : Memory enhancement in healthy older adults using a brain plasticity-based training program: a randomized controlled study. PNAS 2006, 103(33):12523-12528.

12. Oswald W, Gunzelmann T, Rupprecht R: Differential effects of single versus combined cognitive and physical training with older adults: the SimA study in a 5-year perspective. European Journal of Ageing 2006, 3:179-192.
13. Willis S, Tennstedt SL, Marsiske M: Long term effects of cognitive training on everyday functional outcomes in older adults. JAMA 2006, 296:2805-2814

14. Vaynman S: Hippocampal BDNF mediates the efficacy of exercise on synaptic plasticity and cognition. European Journal of Neuroscience 2004, 20:2580-2590.

15. Colcombe SJ, Kramer AF: Fitness effects on the cognitive function of older adults: A meta-analytic study. American Psychological Society 2003, 14(2):125-130.

16. Fabre C, Chamari K, Mucci P: Improvement of cognitive function via mental and/or individualised aerobic training in healthy elderly subject. International Journal of Sports Medicine 2002, 23:415-421.

17. Nithianantharajah J, Hannan A: Enriched environments, experience dependent plasticity and disorders of the nervous system. Nature reviews Neuroscience 2006, 7:697-709.

18. Colcombe SJ, Erickson K, Scalf P, Kim JM, Prahash R: Aerobic exercise training increases brain volume in aging humans. J Gerontol Med Sci 2006, 61A: 1166-1170.

19. Valenzuela MJ, Sachdev P: Assessment of complex mental activity across the lifespan: Development of the Lifetime of Experiences Questionnaire (LEQ). Psychological Medicine 2007, 37(7):1015-1025.

20. Valenzuela MJ, Jones M, Wen W, Rae C, Graham S, Shnier R, Sachdev P: Memory training alters hippocampal neurochemistry in healthy elderly. NeuroReport 2003, 14(10):1333-1337.

21. Levinger I, Goodman C, Matthews V, Hare D, Jerums G, Garnham A, Selig S: $\mathrm{BDNF}$, metabolic risk factors, and resistance training in middle-aged individuals. Medicine and Science in Sports and Exercise 2008, 40(3):535-541.

22. Cassilhas R, Viana V, Grassmann V, Santos RT, Santos RF, Tufik S, Mello MT: The impact of resistance exercise on the cognitive function of the elderly. Medicine and Science in Sports and Exercise 2007, 39(8):1401-1407.

23. Fiatarone Singh M: Exercise comes of age: rationale and recommendations for a geriatric exercise prescription. I Gerontol (MedSci) 2002, 57(A):M262-82.

24. Rosen WG, Mohs RC, Davis KL: A new rating scale for Alzheimer's disease. American Journal of Psychiatry 1984, 141(11):1356-1365.

25. Graham DP, Cully JA, Snow AL, Massman PJ, Doody RS: The Alzheimer's Disease Assessment Scale- Cognitive Subscale. Normative data for older adult controls. Alzheimer Disease and Associated Disorders 2004, 18(4):236-240

26. Hindmarch I, Lehfeld H, De Jongh P, Erzigkeit H: The Bayer Activities of Daily Living Scale (B-ADL). Dementia and Geriatric Cognitive Disorders 1998, 9(SUPPL. 2):20-26.

27. Boutron I, Moher D, Altman D, Schulz K, Ravaud P: Methods and processes of the CONSORT group: Example of an extension for trials assessing non-pharmacologic treatments. Annals of Internal Medicine 2008, 148(4): w-60-w-66.

28. Hughes C, Berg L, Danziger W, Coben L, Martin R: A new clinical scale for the staging of dementia. British Journal of Psychiatry 1982, 140:566-572.

29. Folstein MF: 'Mini-Mental State': A practical method for grading the cognitive state of patients for the clinician. Journal of Psychiatric Research 1975, 12:189-198.

30. Valenzuela MJ, Sachdev P: Brain Reserve and cognitive decline: a non parametric systematic review. Psychological Medicine 2006, 36:1065-1073.

31. Jelic $V$, Kivipelto $M$, Winbald $B$ : Clinical trials in mild cognitive impairment: lessons for the future. J eurol Neurosurg Psychiatry 2006, 77:429-438.

32. de Jager CA, Budge MM, C R: The utility of TICS-M for the assessment of cognitive function in older adults. International Journal of Geriatric Psychiatry 2003, 18(4):318-324.

33. Katz S: Progress in development of the index of ADL. Gerontologist 1970 10(1):20-30.

34. Anderson-Hanley C, Nimon J, Weston S: Cognitive health benefits of strengthening exercise for community-dwelling older adults. Journal of Clinical and Experimental Neuropsychology 2010, 1-6.

35. Marker KR: Marker Software. Heidelberg \& Ladenburg; 1986.

36. Gunther VK, Schafer P, Holzner BJ, Kemmler GW: Long-term improvements in cognitive performance through computer-assisted cognitive training: A pilot study in a residential home for older people. Aging and Mental Health 2003, 7(3):200-206.

37. Borg GAV: Perceived exertion: a note on 'history' and methods. Medicine and Science in Sports and Exercise 1973, 5(2):90-93. 
38. Smith GE, Housen P, Yaffe K, Ruff R, Kennison R, Mahncke H, Zelinski E: A cognitive training program based on principles of brain plasticity: Results from the improvement in memory with plasticity-based adaptive cognitive training (IMPACT). Journal compilation the American Geriatrics Society 2009, 57:594-603.

39. Folquitto JC, Bustamante SEZ, Barros SB, Azevedo D, Lopes MA, Hototian SR, Jacob Filho W, Litvoc J, Bottino CMC: The Bayer - Activities of Daily Living Scale (B-ADL) in the differentiation between mild to moderate dementia and normal aging. Revista Brasileira de Psiquiatria 2007, 29(4):350-353.

40. Bowie CR, Harvey PD: Administration and interpretation of the Trail Making Test. Nat Protocol 2006, 1(5):2277-2281.

41. Strauss E, Sherman E, Spreen O, eds: The Compendium of Neuropsychological Tests. Administration, Norms, and Commentary. Oxford University Press; 32006

42. Sivan $A B$, ed: Benton Visual Retention Test. The Psychological Corporation. Harcourt Brace and Copan; 51992.

43. Clare L, Wilson BA, Carter G, Roth I, Hodges JR: Assessing awareness in early-stage Alzheimer's disease: Development and piloting of the memory awareness rating scale. Neuropsychological Rehabilitation 2002, 12(4):341-362.

44. Andrews FM, Withey SB: Social Indicators of Well-Being: America's Perception of Life Quality. Plenum Press, New York; 1976.

45. Ware JE, Kosinski M, Keller SD: SF-12 How to score the SF-12 Physical and Mental Health Summary Scales. QualityMetric Incorporated, Lincoln, Rhode Island; 31998.

46. Burkhardt CS, Anderson KL: The Quality of Life Scale (QOLS): Reliability, Validity and Utilization. Health and Quality of Life Outcomes 2003, 1-60.

47. Ryff CD, Keyes CLM: The structure of Psychological Well-Being revisited. Journal of Personality and Social Psychology 1995, 69(4):719-727.

48. Lovibond PF, Lovibond SH: The structure of negative emotional states: Comparison of the depression anxiety stress scales (DASS) with the Beck Depression and Anxiety Inventories. Behaviour Research and Therapy 1995, 33(3):335-343.

49. Brink TL, Yesavage JA, Lum O, Heersema P, Adey M, Rose TL: Screening tests for geriatric depression. Clinical Gerontologist 1982, 1:37-44.

50. Koenig H, Westlund R, George L, Hughes D, Blazer D, Hybels C: Abbreviating the Duke Social Support Index for use in chronically ill elderly individuals. Psychosomatics 1993, 34:61-69.

51. Pyo G, Elble RJJ, Ala T, Markwell SJ: The characteristics of patients with uncertain/mild cognitive impairment on the Alzheimer's Disease Assessment Scale- Cognitive Subscale. Alzheimer Disease and Associated Disorders 2006, 20(1):16-22.

52. Erzigkeit H, Lehfeld H, Pena-Casanova J, Bieber F, Yekrangi-Hartmann C, Rupp M, Rappard F, Arnold K, Hindmarch I: The Bayer-Activities of Daily Living Scale (B-ADL): Results from a validation study in three European countries. Dementia and Geriatric Cognitive Disorders 2001, 12(5):348-358.

53. Tombaugh TN, McIntyre NJ: The Mini-Mental State Examination: A comprehensive review. Journal of the American Geriatrics Society 1992, 40(9):922-935.

54. Brodaty H, Pond D, Kem N, Luscombe G, Harging L, Berman K, Huppert F: The GPCog; A new screening test for dementia designed for general practice. Journal of the American Geriatrics Society 2002, 50(3):530-534.

55. Abdulrab K, Heun R: Subjective Memory Impairment. A review of its definitions indicates the need for a comprehensive set of standardised and validated criteria. European Psychiatry 2008, 23(5):321-330.

56. Kaufman AS, Lichtenberger EO, eds: Essentials of WAIS III Assessment. John Wiley \& Sons; 1999.

57. Lezack M, Howieson DB, D W, eds: Neuropsychological Assessment. Oxford University Press; 42004

58. Spreen O, Strauss E, eds: A Compendium of Neuropsychological Tests. Administration, Norms, and Commentary. 2 edition. Oxford University Press; 1998.

59. Yesavage JA, Brink TL, Rose TL, Lum O, Huang V, Adey MB, Leirer VO: Development and validation of a geriatric depression screening scale: a preliminary report. Journal of Psychiatric Research 1982, 17:37-49.

60. Ng F, Trauer T, Dodd S, Callaly T, Campbell S, Berk M: The validity of the 21-item version of the Depression Anxiety Stress Scales as a routine clinical outcome measure. Acta Neuropsychiatrica 2007, 19(5):304-310.

61. Cummins RA: On the trial of the gold standard for subjective wellbeing Social Indicators Research 1995, 43:307-334.
62. Ware JE, Sherbourne CE: The MOS 36-Item Short-Form Health Survey (SF$\left.36^{\oplus}\right)$ : I. conceptual framework and item selection. Med Care 1992, 30(6):473-483

63. Guyatt GH, Sullivan MJ, Thompson PJ: The 6-minute walk: A new measure of exercise capacity in patients with chronic heart failure. Can Med Assoc J 1985, 132:919-923.

64. Guralnick JM, Simonsick EM, Ferrucci L: A short physical performance battery assessing lower extremity function; Association with self reported disability and prediction of mortality in nursing home admission. J Gerontol 1994, 49:M85-M94.

65. Rossiter-Fornoff JE, Wolf SL, Wolfson LI, Buchner DM: A cross-sectional validation study of the FICSIT common data base static balance measures. Frailty and Injuries: cooperative studies of intervention techniques. J of Gerontol And Biol Sci Med Sci 1995, 50:M291-7.

66. Jansen I, Heymsfield SB, Baumgartner RN, Ross R: Estimation of skeletal muscle mass by bioelectrical impedance analysis. Journal of Applied Physiology 2000, 89:465-471.

67. Lulaski HC, Bolonchuk WW, Hall CB, Siders WA: Validation of tetra-polar bioelectrical impedance method to assess human body composition. Journal of Applied Physiology 1986, 60:1327-32.

\section{Pre-publication history}

The pre-publication history for this paper can be accessed here: http://www.biomedcentral.com/1471-2318/11/19/prepub

doi:10.1186/1471-2318-11-19

Cite this article as: Gates et al:: Study of Mental Activity and Regular Training (SMART) in at risk individuals: A randomised double blind, sham controlled, longitudinal trial. BMC Geriatrics 2011 11:19.

\section{Submit your next manuscript to BioMed Central and take full advantage of:}

- Convenient online submission

- Thorough peer review

- No space constraints or color figure charges

- Immediate publication on acceptance

- Inclusion in PubMed, CAS, Scopus and Google Scholar

- Research which is freely available for redistribution

Submit your manuscript at www.biomedcentral.com/submit
C Biomed Central 